\title{
Can subjective sleep quality, evaluated at the age of 73, have an influence on successful aging? The PROOF study
}

\author{
Emilie Crawford-Achour ${ }^{1,2}$, Virginie Dauphinot ${ }^{3}$, Magali Saint Martin ${ }^{4}$, Magali Tardy ${ }^{5}$, \\ Régis Gonthier ${ }^{2}$, Jean Claude Barthelemy ${ }^{1}$, Frédéric Roche ${ }^{1,4}$ \\ ${ }^{1}$ Laboratoire de Physiologie de l'exercice, Equipe SNA Epis EA 4607, Université Jean Monnet, Faculté de Médecine J. Lisfranc,
Hôpital Universitaire, Saint Etienne, France; emilie.achour@chu-st-etienne.fr
${ }^{2}$ Département de Gérontologie Clinique, Université Jean Monnet, Faculté de Médecine J. Lisfranc, Hôpital Universitaire, Saint
Etienne, France
${ }^{3}$ Centre Mémoire de Ressources et de Recherche de Lyon, Hôpital des Charpennes, Hospices Civils de Lyon, Villeurbanne, France
${ }^{4}$ Centre VISAS, Université Jean Monnet, Faculté de Médecine J. Lisfranc, Hopital Universitaire, Saint Etienne, France
${ }^{5}$ Département de Gérontologie Clinique, Université Jean Monnet, Faculté de Médecine J. Lisfranc, Hôpital Général, Saint Chamond,
France
}

Received 17 November 2013; revised 2 January 2014; accepted 12 January 2014

Copyright (C) 2014 Emilie Crawford-Achour et al. This is an open access article distributed under the Creative Commons Attribution License, which permits unrestricted use, distribution, and reproduction in any medium, provided the original work is properly cited. In accordance of the Creative Commons Attribution License all Copyrights (C) 2014 are reserved for SCIRP and the owner of the intellectual property Emilie Crawford-Achour et al. All Copyright (c) 2014 are guarded by law and by SCIRP as a guardian.

\section{ABSTRACT}

Objective: Sleep complaints are recurrent in Geriatrics and are often attributed to physiological aging. The aim of this work is to describe subjective sleep quality and its impact on successful aging. Methods: Subjective sleep quality was evaluated by using the Pittsburgh subjective sleep quality questionnaire. Two visual analogical scales (graduate from 0 to 10 ) were used to quantify perceived state of health and life satisfaction. Objective respiratory sleep parameters were also collected. Results: $\mathbf{3 7 0}$ data were analysed $(\mathbf{4 6 . 2 \%}$ of males). The average age was $73.2+l-1$. The level of perceived state of health was $6.9+l-2$, and life satisfaction level was $7.7+l-2$. Subjective sleep quality was significantly related to perceived health status $(p=0.034)$ and life satisfaction $(p=0.005)$. There was no significant association between sleep quality and objective respiratory sleep parameters. Conclusion: The assessment of sleep quality plays an important role in the management of elderly persons and can help them to age more successfully.

\section{KEYWORDS}

Successful Aging; Sleep Complaint; Pittsburgh Sleep Quality Index

\section{INTRODUCTION}

Aging is associated with objective and subjective sleep modifications. Sleep complaints are a recurrent complaint from the elderly and would seem to affect over $30 \%$ of the population aged over 65 [1]. Sleep complaints can take on many forms and affect various sleep characteristics: sleep duration, sleep performance, numbers of wake-ups and sleep quality. In order to assess sleep complaint, clinicians use the Pittsburgh sleep quality index in clinical practice [2].

It is well-known that poor sleep is associated with an increased risk of mortality [3]. Inefficient sleep can also be predictive of physical decline in subjects over 75 [4]. In addition to the effect on mortality, sleep quality can also impact on psychological and social parameters in an elderly population [4].

Rowe and Kahn characterised successful aging as the reduced probability of developing an illness, the maintenance of a high level of cognitive functioning and the inclination to engage in social and/or productive activities [5]. This concept was subsequently considerably extended to include a psycho-social dimension defining the optimal aging process as one that is accomplished under the best environmental conditions and one that favours the development of remaining capabilities [6].

Numerous studies have focused on the determining factors for successful aging and underline the importance of subjective health perception or well-being as being 
major determining factors of successful aging. For this reason, over recent years, Phelan et al. have reviewed the definition of successful aging by taking into account the perception that the elderly themselves have, in their aging process. The authors therefore highlighted the importance of subjective factors such as happiness, social integration and life satisfaction [7].

Recently, Castro-Lionard et al. have shown that there is a reverse correlation between memory complaint and life satisfaction as well as perceived health status [8]: the level of complaints made by individuals would seem to have an impact on their perception of their own state of health, their life satisfaction and enhance their perceived quality of life.

The aim of this work is to analyse the potential harmful effect that sleep complaint has on successful aging and to demonstrate that individuals with many complaints (sleep, memory or complaints about their morale) potentially have a more negative perception of their state of health and of their aging.

\section{METHOD}

\subsection{Population Studied}

The subjects were those enrolled in the Proof (PRognostic indicator OF cardiovascular and cerebrovascular events) study [9]. The objective of this prospective study was to investigate the predictive value of autonomic nervous system activity on the incidence of cardiovascular and cerebrovascular events. The 1011 subjects of the cohortwere enrolled in the years 2001-2002 by random selection from the electoral rolls of the city of Saint Etienne. Inclusion criteria aimed at subjects aged 65 years at the start of the study. Exclusion criteria were previous myocardial infarction or stroke, atrial fibrillation, insulino-dependant diabetes, cardiac pace-maker, any disease restricting life expectancy to less than 5 years, a contraindication for cerebral MRI, and subjects living in institutions or those intending to move out of the area during the following two years.

\subsection{Subjective and Objective Sleep Parameters}

\subsubsection{Pittsburgh Sleep Quality Index (PSQI)}

Subjective sleep quality was assessed using the French version of the Pittsburgh sleep quality index [10]. The PSQI is a self-assessment questionnaire composed of 19 self-assessment questions and 5 questions reflecting sleep quality during the previous month. Only the selfassessment questions are included in the score. The 19 questions are combined to give 7 components of the global score, each component receiving a score from 0 to 3. In all cases, a 0 score indicates that there is no difficulty whereas a score of 3 indicates the existence of se- vere difficulties. The 7 components of the score are added together to give a global score that goes from 0 to 21 points, 0 meaning that there is no difficulty and 21 , on the contrary, indicating major difficulties. The PSQI is currently used and has been validated in the elderly population [11].

Only the questionnaires correctly filled in with the 19 questions were included in the statistical analysis, the calculation of the components and the global score were taken into account for the study. The PSQI was completed concomitantly to the polygraphic recording.

\subsubsection{Respiratory Ambulatory Polygraphy}

Individuals underwent an ambulatory polygraphy (HypnoPTT device, Tyco Healthcare) to measure objective sleep parameters such as: the apnea/hypopnoea index (AHI), the desaturation index, the desaturation time under $90 \%$, the mean saturation, the minimum saturation. Apneas were defined as a complete arrest of the respiratory flow for at least 10 seconds. Hypopnoeas were defined as a reduction of the amplitude of the respiratory flow of at least $50 \%$ and for at least 10 seconds. This recording was used to detect the presence of a possible obstructive sleep apnea syndrome (OSAS).

An Epworth sleepiness scale was completed concomitantly to the polygraphic recording [12].

\subsection{Evaluation of Perceived State of Health and of Life Satisfaction}

Perceived state of health was measured using a visual analogical scale (VAS) graded from 0 to 10 (0 reflecting very poor perception to 10 an excellent one) in response to the following question taken from the EUROPOL questionnaire [13]: How do you perceive your state of health? Well-being was also assessed by a VAS in line with the same criteria used in the previous question from the "Geriatric Depression Scale" [14]: Are you generally satisfied with your current life?

A multiple choice questionnaire was used to list the different complaints in various domains: autonomy, food intake, communication, thymic complaint, emotional complaint and project elaboration.

Questionnaires were sent to patients' homes and returned by post.

\subsection{Study Schedule}

Objective and subjective sleep measurements were completed between 2006 and 2008 for all the population involved. The questionnaire assessing different complaints and perceived state of health and life satisfaction was completed in 2008.

\subsection{Statistical Analysis}

The SPSS statistical package 15.0 for Windows (SPSS 
Software) was used for statistical analysis. Only those persons who had correctly filled in the Pittsburgh questionnaire and the evaluation of perceived state of health and of life satisfactionwere included in the analysis. The subjects' characteristics were described using mean values and their standard deviations for the quantitative variables and the numbersand frequencies for the qualitative variables. A Chi ${ }^{2}$ test was made to compare subject included and the population not included in the study. The linear correlations between the objective sleep parameters, the perceived state of health, life satisfaction and the total score for the Pittsburgh questionnaire (PSQI) were calculated using the Pearson correlation. Linear regression models were drawn up to test on the one hand, the associations between the PSQI score and the perceived state of health and on the other, the PSQI score and life satisfaction. The models were adjusted with regard to potential confusion factors: sex, age, way of life and educational level. The final models were completed on a step by step analysis and only took into account the variables associated significantly with the PSQI score. The regression coefficients regression (A) and their confidence intervals (CI) at $95 \%$ are presented. The value of the $\mathrm{p}$ was considered as significant if it was lower than 0.05 .

\subsection{Ethics Committee}

The PROOF study was approved by the University Hospital of Saint-Etienne and the (CCPPRB) RhôneAlpes Loire Ethics Committee (CCPPRB). The French Data Protection Authority (CNIL) gave its consent for the data to be entered. All the subjects who took part in the study signed a consent form in a free and informed manner. ClinicalTrials.gov Identifier NCT00759304.

\section{RESULTS}

1) Descriptive analysis

A total of 370 individuals were included in the analysis (Figure 1). Comparison between individuals included and non-included in the study are presented in Table 1. The characteristics of the population under study are presented in Table 2. The average age of the population was $73.2+/-1$. Men accounted for $46.2 \%$ of the population. The majority of the subjects lived with a partner (76.8\%). The VAS scores allocated to the perceived state of health and life satisfaction were respectively $6.9+/-2$ and $7.7+/-2$. Individuals most often complained of memory or thymic difficulties. The total average score obtained with the PSQI was $6.3+/-3.3$. The result allocated to each component is described in Table 2. The individuals usually went to bed at $9 \mathrm{pm}+/-6$ hours and got up at $7.30 \mathrm{am}+/-1$ hour. The average AHI score was 16.8 events per hour $+/-14.2$. The total score on the Epworth sleepiness scale was $5.7+/-3.7$. The mean Mini Mental Status score at baseline of the 370 individuals under study was $28.7+/-1.3$.

2) Correlation between subjective sleep quality, perceived state of health and life satisfaction. Non adjusted

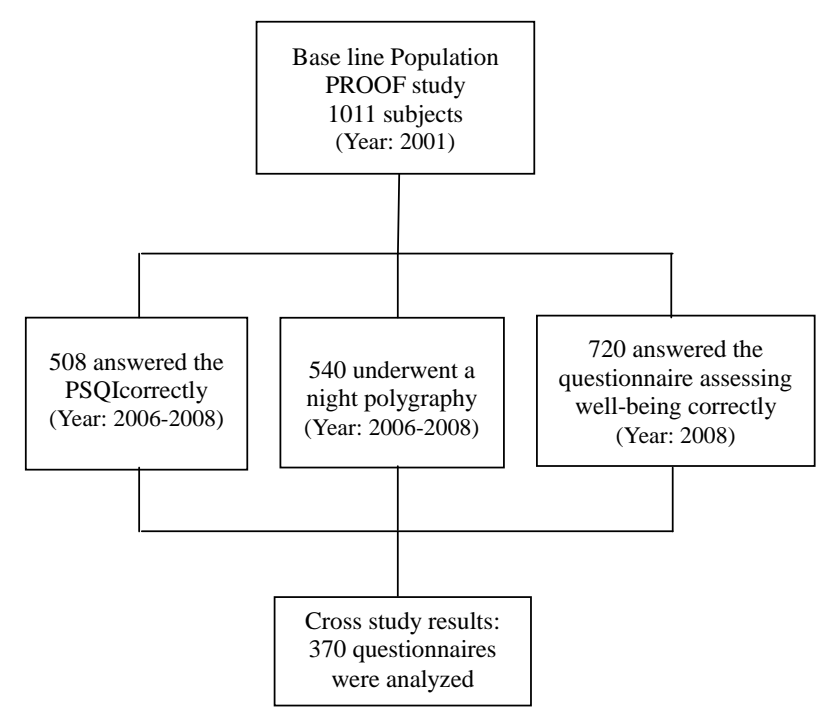

PSQI: Pittsburgh Sleep Quality Index

Figure 1. Study schedule and methodology.

Table 1. Comparison of the population under study and the population not included in the analysis.

\begin{tabular}{|c|c|c|c|}
\hline & \multicolumn{3}{|c|}{ Population included in the analysis $n=370$ Population not included in the analysis $n=641$} \\
\hline & n (\%) & n (\%) & $\mathbf{p}$ \\
\hline Gender (\% men) & $171(46.2 \%)$ & $231(36.0 \%)$ & 0.001 \\
\hline \multicolumn{4}{|l|}{ Educational level } \\
\hline No formal qualifications & $16(4.4 \%)$ & $59(10.3 \%)$ & \multirow{4}{*}{0.003} \\
\hline Primary education certificate & $158(43.4 \%)$ & $247(43.1 \%)$ & \\
\hline Secondary education certificate & $121(33.2 \%)$ & $150(26.2 \%)$ & \\
\hline End of secondary education diploma or over & $69(19.0 \%)$ & 117 (20.4\%) & \\
\hline
\end{tabular}


Table 2. Descriptive analysis of the population studied $(\mathrm{n}=$ 370).

\begin{tabular}{|c|c|c|}
\hline & & $\mathbf{n}$ \\
\hline Age (years) & $73.2+/-1$ & 370 \\
\hline Gender ( $\%$ of men) & 46.2 & 370 \\
\hline Educational level (\% of higher level education) & 22.7 & 366 \\
\hline Lifestyle (\% of persons living alone) & 23.2 & 366 \\
\hline \multicolumn{3}{|l|}{ Pittsburgh sleep quality index } \\
\hline Total score & $6.3+/-3.3$ & 370 \\
\hline Component 1 (Subjective sleep quality) & $1+/-0.6$ & 370 \\
\hline Component 2 (Sleep latency) & $1+/-0.9$ & 370 \\
\hline Component 3 (Sleep duration) & $0.9+/-0.9$ & 370 \\
\hline Component 4 (Habitual sleep efficiency) & $0.8+/-1$ & 370 \\
\hline Component 5 (Sleep disturbances) & $1.2+/-0.4$ & 370 \\
\hline Component 6 (Use of sleep medication) & $0.6+/-1.1$ & 370 \\
\hline Component 7 (Daytime dysfunction) & $0.7+/-1.1$ & 370 \\
\hline Perceived state of health (VAS score out of 10) & $6.9+/-2$ & 356 \\
\hline Perceived life satisfaction (VAS score out of 10) & $7.7+/-2$ & 362 \\
\hline \multicolumn{3}{|l|}{ Difficulty in: } \\
\hline Washing, dressing (\%) & 1 & 315 \\
\hline Going out (\%) & 4.1 & 315 \\
\hline Eating (\%) & 5.7 & 315 \\
\hline Communicating (\%) & 9.5 & 315 \\
\hline Morale (\%) & 16.2 & 315 \\
\hline Memory (\%) & 17.1 & 315 \\
\hline Emotional life (\%) & 8.3 & 315 \\
\hline Planning future activities (\%) & 12.1 & 315 \\
\hline \multicolumn{3}{|l|}{ Polygraphic sleep parameters } \\
\hline Bed time & $9 \mathrm{pm}+/-6$ & 370 \\
\hline Getting up time & $7.30 \mathrm{am}+/-1$ & 370 \\
\hline Desaturation time & $9.3+/-9.5$ & 366 \\
\hline Saturation time $<90 \%$ & $2.6+/-8.4$ & 364 \\
\hline Average $\mathrm{SaO}_{2}$ & $95+/-2$ & 366 \\
\hline Minimum $\mathrm{SaO}_{2}$ & $89+/-7$ & 366 \\
\hline Apnoea Hypopnoea Index & $16.8+/-14.2$ & 367 \\
\hline Score on the Epworth Sleepiness scale & $5.7+/-3.7$ & 364 \\
\hline
\end{tabular}

model:

There was no significant correlation between the objective sleep parameters and the total PSQI score. The relation was also not significant with life satisfaction and perceived health status. Perceived health status and life satisfaction were positively correlated $(\mathrm{r}=0.697$; $\mathrm{p}<$ 0.001). There was also a significant reverse correlation between the total PSQI score and perceived health status $(\mathrm{r}=-0.129 ; \mathrm{p}=0.015)$ and also with life satisfaction $(\mathrm{r}=$ $-0.190 ; \mathrm{p}<0.001)$.

3) Correlation between subjective sleep quality, perceived state of health and life satisfaction. Adjusted model (Table 3).

A step by step regression model that includes sociodemographic parameters and the AHI score showed that the perceived health status was still significantly correlated with the sleep complaint assessed by the PSQI. Also, this relationship remained inversely significant with regard to perceived life satisfaction.

4) Correlation between multiple complaints, perceived state of health and life satisfaction.

Table 3. Linear regression of the global score obtained in the PSQI according to two models (initial model including perceived state of health, sex, age and educational level; final model including perceived state of health and sex). $n=370$.

\begin{tabular}{ccccc}
\hline & \multicolumn{3}{c}{ Perceived health status } \\
\hline A & p & IC $95 \%$
\end{tabular}

Initial model

$\begin{array}{llll}\text { PSQI global score } & -0.072 & 0.028 & {[-0.135 ;-0.008]} \\ \text { Gender } & -0.29 & 0.315 & {[-0.086 ; 0.028]} \\ \text { Educational level } & -0.056 & 0.630 & {[-0.283 ; 0.172]} \\ \text { AHI } & 0.0001 & 0.954 & {[-0.014 ; 0.015]}\end{array}$

Final model

PSQI global score $\quad-0.068 \quad 0.034 \quad[-0.132 ;-0.005]$

Life satisfaction

A $\quad p \quad$ IC $95 \%$

Initial model

$\begin{array}{lrrr}\text { PSQI global score } & -0.109 & 0.001 & {[-0.171 ;-0.046]} \\ \text { Gender } & -0.03 & 0.295 & {[-0.086 ; 0.026]} \\ \text { Educational level } & 0.049 & 0.664 & {[-0.174 ; 0.273]} \\ \text { AHI } & 0.007 & 0.338 & {[-0.007 ; 0.022]}\end{array}$

Final model

PSQI global score $\quad-0.241 \quad 0.005 \quad[-0.410 ;-0.072]$

\section{A: regression coefficient}

CI 95\%: confidence interval 95\%

PSQI: Pittsburgh sleep quality index AHI: apnea-hypopnea index 
Analysing the different types of complaints made by each person, the thymic complaint and the complaint relating to food intake were significantly correlated with the sleep complaint assessed by the PSQI (A: $1.019 \mathrm{p}=$ 0.047 IC 95\% [0.014; 2.024] and A: $1.697 \mathrm{p}=0.04$ IC 95\% $[0.08 ; 3.314])$.

The global complaints score, obtained by adding together the different scores for the various complaints shows a significant correlation with the sleep complaint assessed by the PSQI (A: $0.649 \mathrm{p}<0.0001$ IC 95\% [0.318; 0.98]). This relationship continues after adjustment onthe socio-demographic variables (A: $0.52 \mathrm{p}=$ 0.002 IC 95\% [0.191; 0.848]). There is also a significant reverse correlation between the global complaints score on the one hand and the perceived state of health $(\mathrm{r}=$ -0.398 ; $p$ <.0001) and life satisfaction $(r=-0.488$; $p<$ 0.0001 ). The relationship between the global complaints score and life satisfaction persists in a multi varied analysis and shows the potential impact of multiple complaints on the perceived quality of life (Table 4).

\section{DISCUSSION}

The study suggests that the perceived sleep quality, evaluated by the PSQI, is significantly associated with perceived quality of life. Individuals complained mainly about their thymic statement and their memory. There was a significant correlation between the sleep complaint assessed by the PSQI and the number of other complaints made by the persons interviewed. This shows that individuals who made several complaints tend to situate themselves in a "complaining syndrome" and this has a negative impact on their life satisfaction and their perceived quality of life. Moreover, objective respiratory sleep parameters had no influence on this relationship, confirming the fact that sleep respiratory disturbance was not a confounding factor of this relationship. The EPESE cohort set up in the Eighties with a population aged 73, also showed an association between different sleep complaints and poor state of health indicators [15]. More recently, a Swedish study demonstrated the link between a sleep complaint and a pain complaint within the scope of a global geriatric assessment taking into account the

Table 4. Pearson correlation including the global complaint score, the perceived state of health, life satisfaction and the overall score for the PSQI. $n=370$.

\begin{tabular}{ccc}
\hline & \multicolumn{2}{c}{ Global complaint score } \\
\hline & $\mathrm{r}$ & $\mathrm{p}$ \\
Perceived state of health & -0.398 & $<0.0001$ \\
Life satisfaction & -0.488 & $<0.0001$ \\
PSQI overall score & 0.213 & $<0.0001$
\end{tabular}

PSQI: Pittsburgh sleep quality index. physical, cognitive, psychological and social capacities [16].

If one considers a centenarian as a model for successful aging, it is interesting to observe that in a study carried out by Tafaro et al., $57 \%$ of the centenarians had no sleep complaints. These percentages appear high but are also an argument underlining the idea that sleep quality is a decisive factor for successful aging. Other studies show similar results: Driscoll et al. in a population of 64 persons, aged 75 and over, highlighted a significant association between a better perceived physical state of health evaluated by the SF-36 questionnaire and better sleep quality assessed by the PSQI [17]. There was also no relationship between objective sleep parameters and quality of life. In addition, in a population of 639 persons aged 75 , it was demonstrated that primary insomnia was associated with a lower level of satisfaction with life. [18].

Our results confirm the lack of a relationship between the objective sleep parameters and the PSQI. Kezirian et al. also presented similar results showing that there was no link in elderly persons between the severity of an obstructive sleep pathology and daytime symptoms [19, 20].

However, this present study does have its limitations. Our study focused on individuals under 80 years of age living in their own homes. The more fragile individuals with one or several invalidating pathologies or living in an institution were not taken into account. We cannot exclude the possibility that our findings would be different, had the study focused on the entire age group. Also, there was a statistical difference between individuals under study and the rest of the population. Males were represented more in our study, and this could decrease the influence of gender in our results. The use of the PSQI in an elderly population remains controversial. However, a recent publication from Spira et al. highlighted the internal validity and the high reproducibility of the questionnaire with an elderly male population [21]. We also haven't included micro architectural sleep parameters in this study. Individuals underwent a respiratory polygraphy without any analysis of the neurologic parameters. We can not conclude on the influence that objective sleep quality parameters have on successful aging. Finally, the analysis was completed on cross-sectional data. Thus, we can not either conclude that there is a cause or effect relationship between subjective sleep quality and successful aging.

\section{CONCLUSIONS}

Our study highlights the impact that sleep quality has on successful aging. Too often, this parameter is underestimated despite the fact that its impact on quality of life, as illustrated through diverse studies, appears to be sig- 
nificant.

It would seem necessary that further studies take into account the analysis of sleep micro architecture in the elderly and that its impact on quality of life should be carried out.

\section{REFERENCES}

[1] Ancoli-Israel, S. (2000) Insomnia in the elderly: A review for the primary care practitioner. Sleep, 23, S23-30, S36S38.

[2] Buysse, D.J., Reynolds 3rd, C.F., Monk, T.H., Berman, S.R. and Kupfer, D.J. (1989) The Pittsburgh sleep quality index: A new instrument for psychiatric practice and research. PPsychiatry Research, 28, 193-213. http://dx.doi.org/10.1016/0165-1781(89)90047-4

[3] Dew, M.A., Hoch, C.C., Buysse, D.J., Monk, T.H., Begley, A.E., Houck, P.R., et al. (2003) Healthy older adults; sleep predicts all-cause mortality at 4 to 19 years of follow-up. Psychosomatic Medicine, 65, 63-73. http://dx.doi.org/10.1097/01.PSY.0000039756.23250.7C

[4] Dew, M.A., Reynolds 3rd, C.F., Monk, T.H., Buysse, D.J., Hoch, C.C., Jennings, R., et al. (1994) Psychosocial correlates and sequelae of electroencephalographic sleep in healthy elders. Journal of Gerontology, 49, P8-P18. http://dx.doi.org/10.1093/geronj/49.1.P8

[5] Rowe, J.W. and Kahn, R.L. (1987) Human aging: Usual and successful. Science, 237, 143-149. http://dx.doi.org/10.1126/science.3299702

[6] Baltes, P.B. (1991) The many faces of human ageing: Toward a psychological culture of old age. Psychological Medicine, 21, 837-854. http://dx.doi.org/10.1017/S0033291700029846

[7] Phelan, E.A., Anderson, L.A., LaCroix, A.Z. and Larson, E.B. (2004) Older adults' views of "successful aging”How do they compare with researchers' definitions? Journal of the American Geriatrics Society, 52, 211-216. http://dx.doi.org/10.1111/j.1532-5415.2004.52056.x

[8] Castro-Lionard, K., Thomas-Anterion, C., CrawfordAchour, E., Rouch, I., Trombert-Paviot, B., Barthelemy, J.C., et al. (2010) Can maintaining cognitive function at 65 years old predict successful ageing 6 years later? The PROOF study. Age Ageing, 40, 259-265. http://dx.doi.org/10.1093/ageing/afq174

[9] Barthelemy, J.C., Pichot, V., Dauphinot, V., Celle, S., Laurent, B., Garcin, A., et al (2007) Autonomic nervous system activity and decline as prognostic indicators of cardiovascular and cerebrovascular events: The "PROOF" Study. Study design and population sample. Associations with sleep-related breathing disorders: The "SYNAPSE" study. Neuroepidemiology, 29, 18-28. http://dx.doi.org/10.1159/000108914

[10] Blais FC, Gendron L, Mimeault V, Morin CM (1997) Evaluation of insomnia: validity of 3 questionnaires. En- cephale, 23, 447-53.

[11] Buysse, D.J., Reynolds 3rd, C.F., Monk, T.H., Hoch, C.C., Yeager, A.L. and Kupfer, D.J. (1991) Quantification of subjective sleep quality in healthy elderly men and women using the Pittsburgh Sleep Quality Index (PSQI). Sleep, 14, 331-338.

[12] Kaminska, M., Jobin, V., Mayer, P., Amyot, R., PerratonBrillon, M. and Bellemare, F. (2010)The Epworth sleepiness scale: Self-administration versus administration by the physician, and validation of a French version. Canadian Respiratory Journal, 17, e27-e34.

[13] Brazier, J., Jones, N. and Kind, P. (1993) Testing the validity of the Euroqol and comparing it with the SF-36 health survey questionnaire. Quality of Life Research, 2, 169-180. http://dx.doi.org/10.1007/BF00435221

[14] Yesavage, J.A., Brink, T.L., Rose, T.L., Lum, O., Huang, V., Adey, M., et al (1982) Development and validation of a geriatric depression screening scale: A preliminary report. Journal of Psychiatric Research, 17, 37-49. http://dx.doi.org/10.1016/0022-3956(82)90033-4

[15] Foley, D.J., Monjan, A.A., Brown, S.L., Simonsick, E.M., Wallace, R.B. and Blazer, D.G. (1995) Sleep complaints among elderly persons: An epidemiologic study of three communities. Sleep, 18, 425-432.

[16] Vaz Fragoso, C.A. and Gill, T.M. (2007) Sleep complaints in community-living older persons: A multifactorial geriatric syndrome. Journal of the American Geriatrics Society, 55, 1853-1866. http://dx.doi.org/10.1097/JGP.0b013e3181557b69

[17] Driscoll, H.C., Serody, L., Patrick, S., Maurer, J., Bensasi, S., Houck, P.R., et al. (2008) Sleeping well, aging well: A descriptive and cross-sectional study of sleep in "successful agers" 75 and older. The American Journal of Geriatric Psychiatry, 16, 74-82. http://dx.doi.org/10.1097/JGP.0b013e3181557b69

[18] Hidalgo, J.L., Gras, C.B., Garcia, Y.D., Lapeira, J.T., del Campo del Campo, J.M. and Verdejo, M.A. (2007) Functional status in the elderly with insomnia. Quality of Life Research, 16, 279-286. http://dx.doi.org/10.1093/gerona/glr172

[19] Kezirian, E.J., Harrison, S.L., Ancoli-Israel, S., Redline, S., Ensrud, K., Claman, D.M., et al. (2007) Behavioral correlates of sleep-disordered breathing in older women. Sleep, 30, 1181-1188.

[20] Kezirian, E.J., Harrison, S.L., Ancoli-Israel, S., Redline, S., Ensrud, K., Goldberg, A.N., et al. (2009) Behavioral correlates of sleep-disordered breathing in older men. Sleep, 32, 253-261.

[21] Spira, A.P., Beaudreau, S.A., Stone, K.L., Kezirian, E.J., Lui, L.Y., Redline, S., et al. (2012) Reliability and validity of the Pittsburgh sleep quality index and the Epworth sleepiness scale in older men. The Journals of Gerontology Series A: Biological Sciences and Medical Sciences, 67A, 433-439. http://dx.doi.org/10.1093/gerona/glr172 